\title{
Fiberoptic intubation through a laryngeal mask airway as a management of difficult airwary due to the fusion of the entire cervical spine - A report of two cases -
}

\author{
Jae Jin Lee, Byung Gun Lim, Mi Kyoung Lee, Myoung Hoon Kong, Kyong Jong Kim, and Jea Yeun Lee
}

Department of Anesthesiology and Pain Medicine, Korea University Guro Hospital, Seoul, Korea

Patients with cervical spine instability and limited range of motion are challenge to anesthesiologists. It is important to consider alternatetive methods for securing the airway while maintaining neutral position and minimizing neck motion, because these patients are at increased risk for tracheal intubation failure and neurologic injury during airway management or position change. We experienced two cases that patients had cervical spine instability and severe limited range of motion due to the fusion of the entire cervical spine. One patient was a 6-year-old girl weighing $12.7 \mathrm{~kg}$ and had Klippel-Feil syndrome with Arnold-Chiari malformation, the other was a 24-year-old female weighing $31 \mathrm{~kg}$ and had juvenile rheumatoid arthritis. We successfully performed the intubation by using the fiberoptic intubation though a laryngeal mask airway in these two cases. (Korean J Anesthesiol 2012; 62: 272-276)

Key Words: Arnorl-Chiari malformation, Difficult airway, Fiberoptic intubation, Juvenile rheumatoid arthritis, Klippel-Feil syndrome, Laryngeal mask airway.

Difficult endotracheal intubation is expected when the mobility of the cervical spine is restricted due to unsteadiness of the cervical spine, damage or suspicion of damage to the central nerves, trauma, and malformation such as cervical spine fusion. In such cases the golden standard is to directly view the glottis via fiberoptic bronchoscopy. However only using fiberoptic bronchoscopy can bring technically difficult intubation and patient cooperation becomes very important [1]. In Klippel-Feil syndrome (KFS) the short neck, low hairline, and fusion of the cervical spine creates mobility impairment of the cervical spine. Many patterns of malformation accompany the syndrome. Arnold-Chiari malformation (ACM), which is characterized by the malformation of the craniovertebral junction, affects the nervous system and the muscular-skeleton system [2]. Patients suffering from this are not only difficult to intubate, but if accompanied by ACM, may suffer from neurologic damage due to the extension and flexion of the cervical spine [3]. Juvenile rheumatoid arthritis (JRA) is an autoimmune disease

Received: April 27, 2011. Revised: 1st, June 5, 2011; 2nd, June 30, 2011. Accepted: July 4, 2011.

Corresponding author: Byung Gun Lim, M.D., Department of Anesthesiology and Pain Medicine, Korea University Guro Hospital, 80, Gurodong, Guro-gu, Seoul 152-703, Korea. Tel: 82-2-2626-1437, Fax: 82-2-851-9897, E-mail: bglim9205@yahoo.co.kr

(c) This is an open-access article distributed under the terms of the Creative Commons Attribution Non-Commercial License (http:// creativecommons.org/licenses/by-nc/3.0/), which permits unrestricted non-commercial use, distribution, and reproduction in any medium, provided the original work is properly cited. 
that invades the whole body and its inflammation response is similar to arthritis, pericarditis, and synovitis. Patients with JRA have difficult intubation because of the subluxation of the atlas and axis, fusion of the cervical spine due to arthritis of the cervical spine, glottis stenosis from inflammation of the cricoarytenoid cartilage, and palate defect [4].

Here, we report a case of a child patient and an adult patient whose cervical spine had limited mobility and instability from the disorders mentioned above, which made endotracheal intubation difficult and increased the risk of a neurologic disorder. To reduce the mobility of the cervical spine, a laryngeal mask airway (LMA) was inserted, and was used for successful endotracheal intubation through the LMA fiberoptic bronchoscope.

\section{Case Reports}

\section{Case 1}

A 6-years and 4-months-old child patient ( $124 \mathrm{~cm}, 12.7 \mathrm{~kg}$ ) underwent general anesthesia for ptosis correction surgery 3 years earlier. Because of its reoccurrence, she was admitted in to the hospital for repeated surgery. The child had been diagnosed in the past with KFS. An MRI revealed fusion of the cervical spine bodies, spina bifida, and left atlantooccipital assimilation. In addition, the presence of ACM with cervicomedullary kinking and compression, as well as herniation of the tonsil of the cerebellum was confirmed (Fig. 1). In the surgery that was conducted 3 years earlier, endotracheal intubation using direct

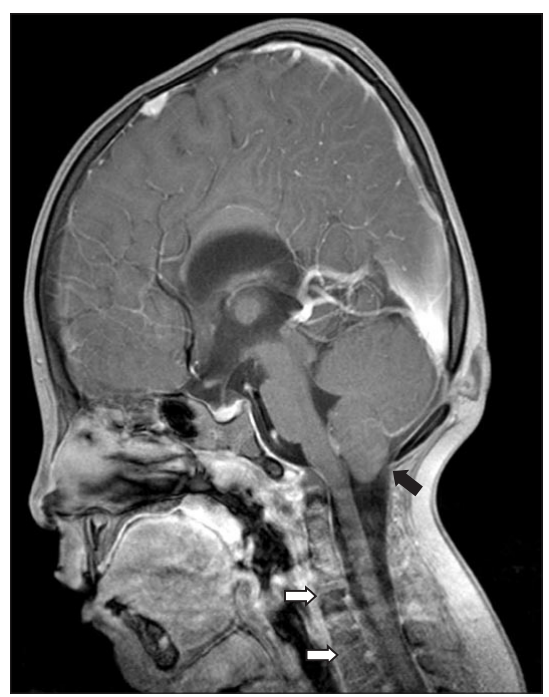

Fig. 1. T1 sagittal brain MRI view. Kinking and compression of medulla oblongata and somewhat herniation of the tonsil of the cerebellum are noted in cervicomedullary junction (black arrow). Also, fusion of the entire cervical spine is noted (white arrows). laryngoscopy was performed, but was uneventful.

The physical exam showed a short neck with very limited movement. The mouth opening at its maximum was $3 \mathrm{~cm}$ in interincisional distance, the thyromental distance from the thyroid notch to the tip of the chin was $5 \mathrm{~cm}$, and the Mallampati score was 2. Cervical spine fusion, compression of the medulla oblongata and herniation of the tonsil of the cerebellum were observed, so extension of the cervical spine was difficult. Therefore, it was expected that endotracheal intubation via direct laryngoscopy would not be easy. There was also a high possibility of neurological damage from extension, so endotracheal intubation had to maintain neck movement as little as possible. Therefore, intubation via awake fiberoptic bronchoscopy was first considered. However, getting patient cooperation for awake endotracheal intubation was difficult since the patient was a child. Therefore, after the induction of general anesthesia, an LMA (LMA-Classic ${ }^{\mathrm{TM}}$, The Laryngeal Mask Company, Henley on Thames, UK) was first inserted as it controlled the airway and minimized movement of the cervical spine. Through the LMA, a fiberoptic bronchoscope (Olympus LF-GP, Olympus Optical Company, Tokyo, Japan) with an outer diameter of $4.1 \mathrm{~mm}$ was inserted for endotracheal intubation.

For premedication, atropine $0.2 \mathrm{mg}$ intramuscular was given, and for induction propofol $30 \mathrm{mg}$ intravenous was given. After the loss of eyelid reflex and voluntary respiration, it was confirmed that there was no malfunction with manual ventilation, and rocuronium $9 \mathrm{mg}$ was injected. The assistant maintained manual in-line stabilization [5], inserted an LMA 2.5, and confirmed that ventilation was adequate. It had previously been confirmed that an uncuffed endotracheal tube (Sheridan/Uncuffed ${ }^{\mathrm{TM}}$, Teleflex Medical, Pennsylvania, USA) with a $5.0 \mathrm{~mm}$ internal diameter was able to smoothly pass the LMA 2.5 . At the end of the 5.0 $\mathrm{mm}$ internal diameter uncuffed endotracheal tube, another $4.5 \mathrm{~mm}$ internal diameter uncuffed endotracheal tube had been connected and slipped over the fiberoptic bronchoscopy previously to easily remove the LMA after endotracheal intubation. The swivel adapter was connected to the LMA while maintaining ventilation. Following that, the fiberoptic bronchoscope with the endotracheal tube advanced over it was inserted through the LMA (Fig. 2). The visibility of the vocal cord by fiberoptic bronchoscopy was graded as A and B using Brimacombe et al. [6] scoring system. A and B, respectively, were grade 3 (vocal cords plus posterior epiglottis visible) and grade 2 (26-50\% of vocal cords visible), so they had relatively poor visibility, and the area around the vocal cord was considerably distorted. Therefore, the fiberoptic bronchoscope could not directly pass the vocal cord. The fiberoptic bronchoscope was slightly flexed up and down, and then advanced. It passed the vocal cord without any difficulty and was able to advance into the trachea. After confirming the bronchial cartilage, 


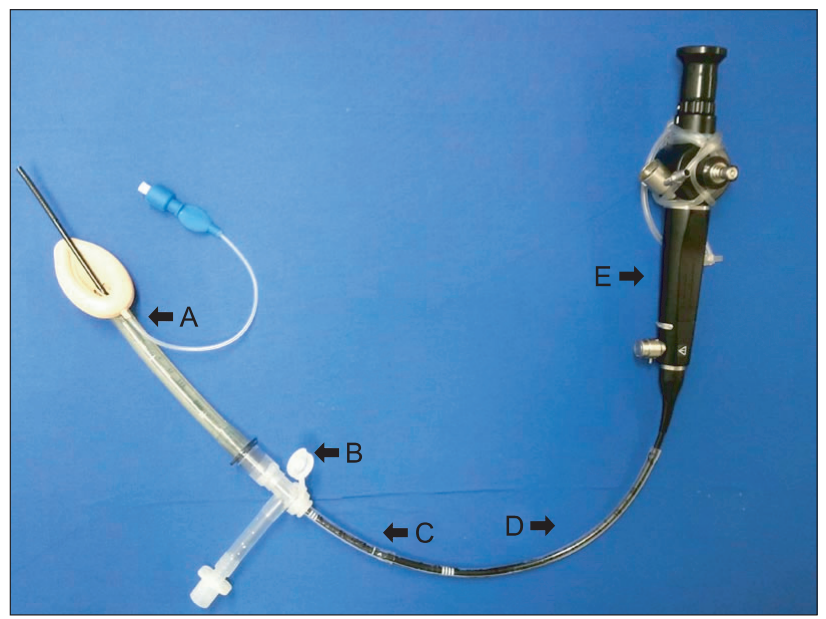

Fig. 2. Telescoping of the endotracheal tubes over a fiberoptic bronchoscope through the laryngeal mask airway. (A) laryngeal mask airway, (B) swivel adapter, (C) uncuffed endotracheal tube (ID $5.0 \mathrm{~mm}$ ), (D) uncuffed endotracheal tube (ID $4.5 \mathrm{~mm}$ ), (E) fiberoptic bronchoscope.

the prepared endotracheal tube was slid over the fiberoptic bronchoscope. There was slight resistance near the vocal cord but the endotracheal tube was advanced uneventfully, and this was confirmed by fiberoptic bronchoscopy. To ensure that the endotracheal tube was not pushed out, it was held firmly while the bronchoscope and the LMA were removed in succession. Afterwards the endotracheal tube connected at the distal end was also removed. By auscultation, the balance of the right and left breath sounds were confirmed, and the endotracheal tube was secured in place. At this point the depth of the endotracheal tube from the teeth was $15 \mathrm{~cm}$. The total time of endotracheal intubation from muscle relaxant iv administration was $5 \mathrm{~min}$. Immediately after intubation, blood pressure, heart rate, and hemodynamic changes were within $20 \%$ of the baseline.

During this time, oxygen saturation for the patient did not decline. Anesthesia maintenance was performed with total intravenous anesthesia (TIVA) using profopol and remifentanil. In the perioperative period, there was no ventilation malfunction or airway-related complications. The patient was healthy when discharged 3 days after surgery.

\section{Case 2}

A 24-years-old female patient $(140 \mathrm{~cm}, 31 \mathrm{~kg})$ had been under follow-up observation since she was 5 years-old for juvenile rheumatoid arthritis (JRA) with the department of internal medicine. There were no past anomalies in her family history and she had JRA spread to her whole body. She complained of severe pain in her right knee and scheduled a right-knee synovectomy with an orthopedist. An x-ray of the

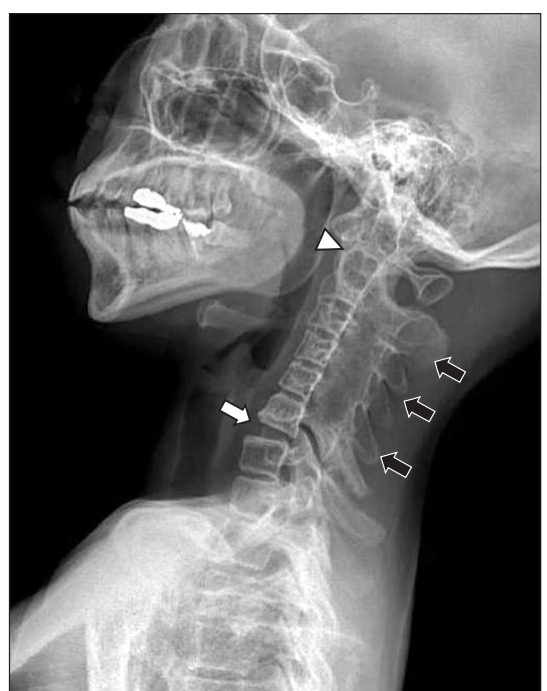

Fig. 3. Extension lateral view of cervical spine X-ray. Posterior facet fusion at C2-6 (black arrows), suspected basilar invagination of odontoid process and atlantoaxial subluxation are noted (arrow head). Also, mild retrolisthesis at C6/7 with facet arthrosis are noted (white arrow).

cervical spine showed a fusion of the posterior facets from C2 to $\mathrm{C} 6$, a suspected basilar invagination of the odontoid processes, and a mild retrolisthesis at $\mathrm{C} 6 / 7$, as well as facet arthrosis (Fig. 3). The physical exam showed that the flexion and extension of the cervical spine were almost impossible and the interincisional distance was $2.5 \mathrm{~cm}$, the thyromental distance was about $3 \mathrm{~cm}$, and the Mallampati score was 4 . The patient was extremely fearful of awake fiberoptic bronchoscopy and refused it. Therefore we decided upon the intubation method used in Case 1. As premedication, glycopyrrolate $0.2 \mathrm{mg}$ and midazolam 2 $\mathrm{mg}$ im were administered. For anesthesia induction, thiopental $150 \mathrm{mg}$ iv was administered. After the loss of eyelid reflex and voluntary respiration, it was confirmed that mechanical ventilation was functioning without any problems. The physical exam showed the oral axis and pharyngolaryngeal axis were almost straight, and cervical movement was almost impossible. It was judged that either LMA insertion failure or ventilation failure was likely to occur. Therefore, as a muscle relaxant, succinycholine $30 \mathrm{mg}$ iv was administered. After muscle relaxation, the insertion of an LMA 3.0 was attempted. There was resistance in gliding over the pharngolarynx, but intubation was successful without difficulty. By auscultation, one could hear the slight sound of gas leaking around the LMA. However, tidal volume $(250 \mathrm{ml})$ loss was under $20 \%$ and $\mathrm{ETCO}_{2}$ was $30-$ $40 \mathrm{mmHg}$, and oxygen saturation was maintained at $100 \%$.

In the same manner as Case 1, the endotracheal tube which was set over the fiberoptic bronchoscope, maintained ventilation via the swivel adapter and was inserted into place. It was previously confirmed that the cuffed endotracheal tube with 
the $5.0 \mathrm{~mm}$ internal diameter (Sheridan $/ \mathrm{CF}^{\circledR}$, Teleflex Medical, Pennsylvania, USA) smoothly passed over the cuff and the LMA 3.0, and the distal end of this tube was connected to the $4.5 \mathrm{~mm}$ noncuffed endotracheal tube, which made the removal of the LMA easier. The visibility around the vocal cord with the fiberoptic bronchoscopy was grade 3 (vocal cords plus posterior epiglottis visible) and grade 2 (26-50\% of vocal cords visible), which resulted in relatively poor visibility. However, with small up and down flexions of the fiberoptic bronchoscope, it was possible to advance through the vocal cord and into the trachea, and intubation was successfully performed in the same manner as in Case 1. In the perioperative period, there were no impediments to ventilation or airway-related complications. The patient was healthy when discharged on post-surgery day 10 .

\section{Discussion}

When a difficult airway is expected or damage in the cervical spine is suspected, endotracheal intubation via awake fiberoptic bronchoscopy is recommended as a safe and sure way of airway control. However, Johnson et al. [7] stated that with endotracheal intubation via fiberoptic bronchoscopy, the failure rate of the first try is high (approximately 53.3\%), which means it requires great skills and acquired experience.

Awake endotracheal intubation can also cause great stress to the patient. One of its drawbacks is that it is very difficult to perform with uncooperative patients, especially children. Therefore, this procedure is performed in sedated patients, but this also requires great skills that are acquired from extensive experience. The drawback is that the longer the time is required for endotracheal intubation, the greater the risk of hypoxic injury from ventilation impairment. On the other hand, LMA insertion, which is often used in difficult intubations, is easy to learn and does not require acquired skills, implying it is relatively easy to perform. When necessary, they can be performed without intravenous administration of muscle relaxants, and awake intubation is possible depending on the situation [8]. However, the use of the LMA is not appropriate for long surgeries, when continuous mechanical ventilation is required after surgery, when position changing is needed, when there is a risk of the inhalation of gastric content, and in oral surgeries.

We attempted to design a method where awake fiberoptic bronchoscopy and the LMA complement each other. One concern in applying such a method to the present cases was that patients who have a high risk of neurologic damage due to the immobility or the mobility of the cervical spine need to have airway control without moving the cervical spine. Therefore, LMA insertion and ventilation may not seem appropriate. However, even when the mobility of the cervical spine is limited, there have been reports that the insertion of the LMA was possible without moving the cervical spine, and there have been reports on the insertion of the LMA without moving the cervical spine in KFS patients accompanied with congenital cervical fusion $[8,9]$. Also, it has been reported that LMA insertion moves the cervical spine less than general endotracheal intubation via direct laryngoscopy and mask ventilation using chin lifts and jaw thrusts [10]. Based on this, after anesthesia induction, the authors successfully performed LMA insertion hardly moving the cervical spine, and appropriate ventilation was also confirmed. Inserting the LMA after the induction of general anesthesia in the manner above has the benefits of making intubation possible in children and in uncooperative adults and minimizing hemodynamic responses to stimulation.

In addition, endotracheal intubation using a swivel adapter when ventilation is possible, as the authors have done, can minimize the risk of hypoxic injury during endotracheal intubation, and be performed safely without haste.

There is the blind intubation method via LMA, which is without fiberoptic bronchoscopy. However, according to Brimacombe [6], after placement of the LMA, the optic vision from fiberoptic bronchoscopy may not show the glottis exposed. When the mobility of the cervical spine is severely limited as in the presented case, blind intubation is not only difficult but the intubation tube can also cause airway damage. In fact, there are reports on unilateral vocal cord paralysis occurring from blind intubation performed with intubation-use LMAs [11]. Therefore using fiberoptic bronchoscopy has a greater success rate and is safer than blind intubation.

Recently, many devices have been developed that can be used for difficult endotracheal intubation. Some examples are the Bonfils intubation fiberscopy, Glidescope ${ }^{\circledR}$, Airtraq optical laryngoscope, which are reported to have been used in difficult airways for successful endotracheal intubation [12-14]. However, their drawbacks include being very costly and requiring great skill to use them. The authors used endotracheal tubes and LMAs that are commonly used and easy to purchase, as well as fiberoptic bronchoscopes, which are usually purchased by most hospitals. We were interested in a method that did not require purchasing any additional equipment and wanted to report that this method would be useful for patients with greatly limited mobility.

We introduced a method that required consideration of the external diameter of the fiberoptic bronchoscope, internal diameter of the LMA, and both the internal and external diameters of the endotracheal tube before endotracheal intubation. Kim et al. [15] reported on similar considerations, but we used fiberoptic bronchoscopy, which had a different external diameter size. The products used at each hospital are different, so before surgery, one must check if the passage of devices through another is easy. Older patients especially 
need endotracheal tubes that are able to be intubated and allow adequate ventilation, but their internal and external diameters are larger than those of a LMA and cannot pass through it. Therefore, endotracheal intubation is first performed with an endotracheal tube with small enough internal and external diameters to easily pass through the LMA. Then one can consider changing endotracheal tubes by using a tube exchanger. A simple method of intubation is using a lightwand from the beginning. Using a lightwand is relatively easy to learn and is inexpensive. Although it cannot be performed simultaneously with ventilation, it can be used in patients with good ventilation, such as the patient from Case 2 who used mask ventilation. Thus solely using this one device makes performing intubation much simpler.

In conclusion, endotracheal intubation using fiberoptic bronchoscopy via LMA after anesthesia induction is easy and safe in patients accompanied by general cervical fusion, who are expected to have difficult endotracheal intubation. This method allows for soft endotracheal intubation. In the present report, it was only performed on patients with a cervical spine problem. However, this method can be considered as a substitute or complementary for patients expected to have difficult airways due to other causes.

\section{References}

1. Parnell JD, Mills J. Awake intubation using fast-track laryngeal mask airway as an alternative to fiberoptic bronchoscopy: a case report. AANA J 2006; 74: 429-31.

2. Nagib MG, Maxwell RE, Chou SN. Identification and management of high-risk patients with Klippel-Feil syndrome. J Neurosurg 1984; 61: 523-30

3. Vannemreddy P, Nourbakhsh A, Willis B, Guthikonda B. Congenital Chiari malformations. Neurol India 2010; 58: 6-14.

4. Takenaka I, Aoyama K, Iwagaki T, Ishimura H, Takenaka Y, Kadoya T. Fluoroscopic observation of the occipitoatlantoaxial complex during intubation attempt in a rheumatoid patient with severe atlantoaxial subluxation. Anesthesiology 2009; 111: 917-9.

5. Hastings RH, Wood PR. Head extension and laryngeal view during laryngoscopy with cervical spine stabilization maneuvers. Anesthesiology 1994; 80: 825-31.

6. Brimacombe J, Keller C. Does efficacy of seal and fibreoptic view change during anaesthesia with the laryngeal mask airway: a comparison of oxygen and oxygen-nitrous oxide gas mixtures. Acta Anaesthesiol Scand 2000; 44: 1258-60.

7. Johnson DM, From AM, Smith RB, From RP, Maktabi MA. Endoscopic study of mechanisms of failure of endotracheal tube advancement into the trachea during awake fiberoptic orotracheal intubation. Anesthesiology 2005; 102: 910-4.

8. Kannan S, Chestnutt N, McBride G. Intubating LMA guided awake fibreoptic intubation in severe maxillo-facial injury. Can J Anaesth 2000; 47: 989-91.

9. Stallmer ML, Vanaharam V, Mashour GA. Congenital cervical spine fusion and airway management: a case series of Klippel-Feil syndrome. J Clin Anesth 2008; 20: 447-51.

10. Brimacombe J, Keller C, Kunzel KH, Gaber O, Boehler M, Puhringer F. Cervical spine motion during airway management: a cinefluoroscopic study of the posteriorly destabilized third cervical vertebrae in human cadavers. Anesth Analg 2000; 91: 1274-8.

11. Mun CS, Kim HT, Heo HE, Lee JH, Kwon YE. Unilateral vocal cord palsy occurred after difficult endotracheal intubation using intubating laryngeal mask airway - A case report -. Korean J Anesthesiol 2009; 56: 200-3.

12. Choi GS, Park SI, Lee EH, Yoon SH. Awake Glidescope ${ }^{\circledR}$ intubation in a patient with a huge and fixed supraglottic mass -A case report-. Korean J Anesthesiol 2010; 59: S26-9.

13. Kim SH, Woo SJ, Kim JH. A comparison of Bonfils intubation fiberscopy and fiberoptic bronchoscopy in difficult airways assisted with direct laryngoscopy. Korean J Anesthesiol 2010; 58: 249-55.

14. Park SJ, Lee WK, Lee DH. Is the Airtraq optical laryngoscope effective in tracheal intubation by novice personnel? Korean J Anesthesiol 2010; 59: 17-21.

15. Kim JE, Chang CH, Nam YT. Intubation through a Laryngeal Mask Airway by Fiberoptic Bronchoscope in an Infant with a Mass at the Base of the Tongue. Korean J Anesthesiol 2008; 54: S43-6. 